\title{
SISTEM MONITORING ALARM PERINGATAN BANJIR DAN FITUR MOTOR SERVO UNTUK BUKA TUTUP PINTU AIR MENGGUNAKAN ALGORITMA BACKGROUND SUBTRACTION
}

\author{
Septa Najibul Wahid ${ }^{1}$, Anggit Dwi Hartanto ${ }^{2}$ \\ 1,2 Fakultas Informatika, Universitas Amikom Yogyakarta, Indonesia \\ Email: ${ }^{1}$ septa.wahid@students.amikom.ac.id, ${ }^{2}$ anggit@amikom.ac.id
}

(Naskah masuk: 12 Januari 2021, diterima untuk diterbitkan: 23 Juni 2021)

\begin{abstract}
Abstrak
Bencana alam di Indonesia masih sangat di takut kan dan akhir akhir ini sering terjadi bencana yang sering terjadi yaitu bencana Banjir, Banjir masih menjadi ancaman bencana yang dampak nya sangat berbahaya di Indonesia, sering kali menelan banyak korban. Oleh karena itu Penelitian ini bertujuan untuk membuat system monitoring alarm banjir dan motor servo untuk membuka dan menutup pintu air nya ke dataran yang lebih tinggi, sistem ini di hubungkan secara online sebagai informasi alarm terhadap terjadinya banjir. Untuk monitoringnya menggunakan teknologi masakini yaitu Internet of things (IoT) agar informasi level dapat dipantau secara real time. Dan untuk alatnya yaitu menggunakan Water level sensor digunakan sebagai pembaca data, buzzer untuk alarm nya jika status nya berada di tingkatan bahaya dan Node MCU ESP2866 sebagai pemroses dan mengirimkan data secara nirkabel ke smartphone android lewat aplikasi BLYNK, hasil penelitian ini adalah suatu system ini untuk mendeteksi ketinggian air nya dan memunculkan status nya yaitu status aman, status siaga, dan status bahaya dan jika ketinggian nya sudah mencapai status bahaya maka alarm di alat buzzer nya itu akan berbunyi dan secara otomatis pintu air di motor servo nya itu akan membuka/membuang air tersebut, serta di penelitian ini menggunakan metode algoritma background subtraction yg berguna untuk memantau grafik obyek ketinggian air nya. Dengan demikian system ini akan bermanfaat untuk masyarakat dan terutama di daerah dataran rendah agar tidak terjadinya banjir
\end{abstract}

Kata kunci : iot, blynk, nodemcu, banjir, arduino, background subtraction.

\section{FLOOD WARNING ALARM MONITORING SYSTEM AND SERVO MOTOR FEATURES TO OPEN AND CLOSE THE FLOOD DOORS USING BACKGROUND SUBTRACTION ALGORITHM}

\begin{abstract}
Natural disasters in Indonesia are still very much feared and lately there have been frequent disasters that often occur, namely floods, floods are still a threat to disasters whose impacts are very dangerous in Indonesia, often claiming many victims. Therefore, this study aims to create a flood alarm monitoring system and a servo motor to open and close the floodgates to higher ground, this system is connected online as alarm information against the occurrence of floods. For monitoring it uses current technology, namely the Internet of things (IoT) so that level information can be monitored in real time. And for the tool, it uses a Water level sensor that is used as a data reader, a buzzer for the alarm if the status is in a dangerous level and the ESP2866 MCU Node as a processor and sends data wirelessly to an android smartphone via the BLYNK application, the results of this study are a system for detects the water level and brings up its status, namely safe status, standby status, and danger status and if the height has reached the danger status then the alarm on the buzzer will sound and automatically the floodgate on the servo motor will open / throw water and in this study using the background subtraction algorithm method which is useful for monitoring the graph of the object's water level. Thus this system will be useful for the community and especially in low-lying areas to prevent flooding
\end{abstract}

Keywords: iot, blynk, nodemcu, banjir, arduino, background subtraction 


\section{PENDAHULUAN}

Belakangan ini bencana alam di Indonesia sangat sering terjadi, yang utama nya adalah bencana banjir, di Indonesia sering kali mengalami banjir dan sering mengakibatkan jatuh nya banyak korban, dan banyak kerugian secara material dan lain lain, di karnakan terjadinya air meluap di kali, sehingga di daerah yang rawan dan dataran nya rendah sering sekali terjadi banjir[1], pada kali ini penulis akan membuat alat system monitoring alarm ketinggian banjir, untuk mengetahui informasi tentang ketinggian banjir, untuk memonitoring nya menggunakan teknologi yaitu IoT ( Internet of Things) dan untuk rangkaian alat nya itu terdiri dari Node MCU, Waterlevel sensor, Led, dan motor servo[2]. Disini penulis juga untuk melakukan penelitiannya menggunakan metode algoritma background subtraction, jadi metode background subtraction itu adalah metode algoritma yang mendeteksi gerak suatu objek, metode tersebut akan mendeteksi gelombang air nya menggunakan kamera, dan ketika di deteksi apakah gelombang air nya sudah mencapai batas ketinggian atau belum, alasannya menggunakan metode tersebut karna metode background subtraction cukup efektif jika di implementasikan ke system monitoring banjir ini[3]. Hasil sementara jika nanti alat nya akan di taruh di hilir sungai, kali dan yang terutama, yang sering terjadinya banjir, dan nanti juga akan ada kamera untuk memantau nya, jadi alur nya yaitu jika lampu led nya berwarna hijau maka status aman, jika led berwarna kuning, status siaga, jika led berwarna merah status akan waspada, dan jika status sudah mencapai status waspada maka buzzer akan menyala dan motor servo nya akan membuang air ke dataran yg lebih tinggi, dengan itu akan membuat ancaman bahaya banjir akan berkurang dengan ada nya alat sistem tersebut[4].

\section{LITERATUR REVIEW}

\subsection{Dasar Teori}

\subsubsection{Internet of Things}

Internet of Thing (IoT) dapat di artikan sebagai sebuah benda penelitian sendiri semenjak berkembang nya teknologi internet dan teknologi lainnya, menjadikan bahwa IoT salah satu cara untuk memulai penelitian dan sudah banyak penelitian yang menggunakan teknologi IoT, IoT juga bisa di gambarkan seperti ponsel pintar, Internet $\mathrm{Tv}$ dan sensor. Dengan cara kerja IoT yaitu cukup menghubungkan dengan koneksi internet yang menghubungkan dengan benda dan IoT dalam penerapannya dapat memantau objek, mengindentifikasi, melacak, dan menemukan[5].

\subsubsection{Blynk}

Blynk merupakan platform untuk aplikasi OS Mobile yg di rancang untuk layanan IoT yang di rancang untuk membuat remote control pada module esp8266, arduino, raspberry $\mathrm{Pi}$, dan sensor[6].

\subsubsection{Background Substraction}

Background Subraction yaitu suatu metode algoritma yg mendeteksi sebuah objek dan objek itu bisa berupa foto atau video[7]

\subsection{Review Jurnal}

Dalam penelitian ini, penulis melakukan beberapa studi literature untuk menemukan beberapa masalah dan untuk mempermudah penulis dalam menyusun penelitian. Beberapa penelitian pernah dilakukan oleh beberapa orang mengenai sistem monitoring alarm ketinggian banjir

Pada penelitian sebelumnya[8] membahas mengenai "Peringatan bencana banjir cerdas dengan cepat: mengembangkan platform manajemen berbasis IoT dan menggunakan 2 kelas jaringan saraf untuk memprediksi status banjir" pada penelitian ini berfokus untuk mencegah bencana banjir yang sering melanda.

Output dari penelitian ini ialah suatu alat yg tujuan nya untuk mengetahui peringatan banjir dini, dan di penelitian ini menyiapkan 3 alat yaitu nodeMCU, sensor ketinggian air dan sensor aliran, untuk metode nya yakni menggunakan metode

2 kelas jaringan saraf tiruan. Penelitian di awali dari proses pembuatan rangkaian untuk peringatan banjir, dan untuk informasi nya akan di kirimi melewati layanan web, dan sistem pemantauan nya akan mengetahui grafik pemantauan ketinggian banjir, pemantauan laju air dan status banjir.

Pada penelitian sebelumnya[9] membahas mengenai "Perancangan Sistem Peringatan Banjir Berbasis IoT dan Karakteristik Air" pada penelitian berfokus pada mengurangi tingkat kematian jiwa dan mengurangi kerugian atas dampak bencana banjir, penelitian ini terdapat 2 faktor penting utama yaitu ketepatan deteksi banjir dan ketetapan penanganan informasi.

Untuk bahan nya menggunakan mikrokontroler NodeMCU dan sensor nya menggunakan 2 sensor yaitu sensor ultrasonic dan sensor kecepatan air, jadi sistem kerja nya yaitu nanti untuk informasi nya akan di kirimi melewati web serta notifikasi dan jika status sudah mencapai tingkat waspada nanti akan muncul suara peringatan dini, dengan ada sistem peringatan banjir tersebut akan mengurangi atau mencegah banyaknya kerugian harta benda dan nya, dan masyarakat juga bisa memantau dengan sendiri status level ketinggian air tersebut.

\section{METODE PENELITIAN \\ 3.1. Rancangan Alur Penelitian}

Pada penelitian ini menggunakan metode research and development $(\mathrm{R} \& \mathrm{D})$ dimana metode ini adalah dapat menghasilkan produk tertentu dan dapat menguji ke efektifan produk tersebut. Pada gambar 1 
step pertama di awali dengan pengumpulan data, untuk datanya tersebut dapat di peroleh dari referensi referensi lainnya seperti jurnal, paper atau artikel penelitian, selanjutnya mencari algoritma yang tepat untuk penelitian ini, disini menggunakan algoritma background surbraction, kemudian lanjut melakukan perancangan pada sistem dan alat, setelah semua sudah di rancang dan sudah selesai maka lanjut dengan kita lihat hasil dan kesimpulan.

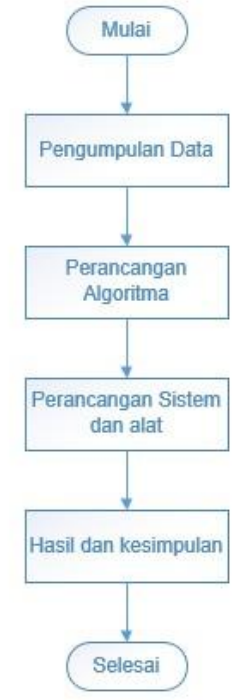

Gambar 1. Alur Penelitian

\subsection{Rancangan Penerapan Algoritma Background Subraction}

Penelitian ini menggunakan metode algoritma background subtraction yaitu untuk memantau ketinggian banjir sudah melebihi batas atau belum dan alat nya yaitu menggunakan kamera, jadi bisa beruba foto dan video hasil nya, algoritma background subtraction adalah sebuah metode yg dapat mendeteksi objek-objek berupa foreground, dengan cara mencari perbandingan antara frame dan gambar background dari layer statistik. Jadi nanti untuk mendeteksi atau cara kerja nya yaitu kamera akan terpasang di sisi hilir sungai atau kali, dan nanti kamera tersebut atau algoritma tersebut dapat mendeteksi suatu objek yg bergerak. Jadi alur sistem nya yaitu:

a. Kamera aktif dan menangkap suatu objek bergerak dan di lakukan secara manual, dengan resolusi kamera yang perlu di setting terlebih dahulu.

b. Hasil penangkapan kamera dapat berupa video untuk melacak skala penunjukan jika sensor sudah mencapai ketinggian

c. Saat air sudah mencapai ketinggian $0-2 \mathrm{~m}$ maka sensor tersebut menandakan bahwa level masih Aman, jika ketinggian nya sudah mencapai $3-5 \mathrm{~m}$ maka sensor tersebut menandakan bahwa sudah mulai ke level Waspada, dan jika ketinggian nya sudah mencapai 6-10 m maka status level nya sudah bahaya dan kamera tersebut akan mendeteksi lalu buzzer atau alarm nya akan menyala, maka akan secara otomatis alat motor servo akan membuka pintu air nya tersebut.

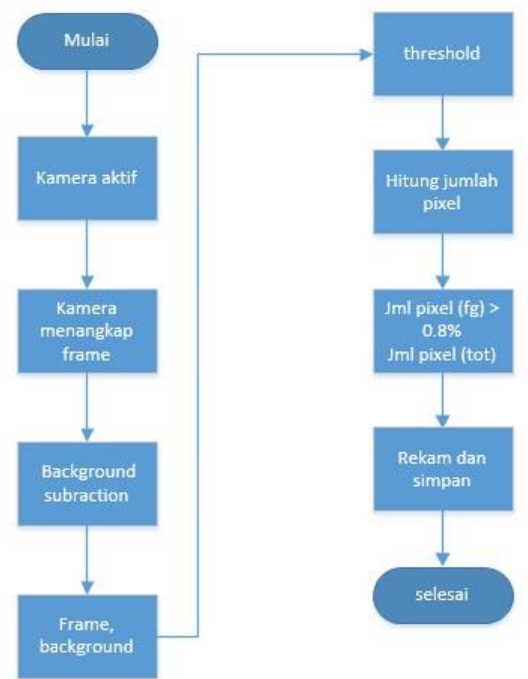

Gambar 2. Diagram alur algoritma Background Subraction

\subsection{Rancangan Alur Sistem}

Sistem deteksi ini menggunakan 1 alat yaitu sensor water level untuk mendeteksi ketinggian banjir nya, yang akan di pasangkan ke tempat yang rawan banjir dan informasi nya di kirimkan ke blynk yang sudah terpasang di smartphone, data tersebut akan bisa dilihat secara realtime di aplikasi blynk dan arduino nya, lalu pengguna nya bisa melihat nya melalui smartphone masing masing yang sudah terinstall aplikasi tersebut.

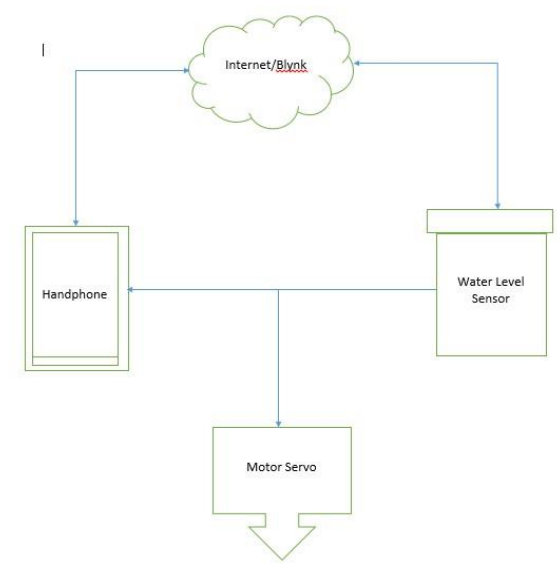

Gambar 3. Alur Sistem Deteksi Ketinggian Banjir

\subsection{Rancangan Alat}

Untuk rancangan alat disini peneliti menggunakan alat Node MCU, LED, Water level sensor, Motor servo, Buzzer. Berikut penjelasan alat nya:

\section{a. NodeMcu}

Yaitu sebuah platform yang berbasis open source, NodeMcu juga adalah sebuah perangkat microcontroller tetapi microcontroller ini sudah 
ada module wifi esp8266, NodeMcu ada beberapa versi diantara nya adalah : NodeMcu 0.9 , NodeMcu 1.0, NodeMcu 1.0(unofficial board). Rata rata yang di pake saat ini adalah NodeMcu 1.0 yang versi LoLin.

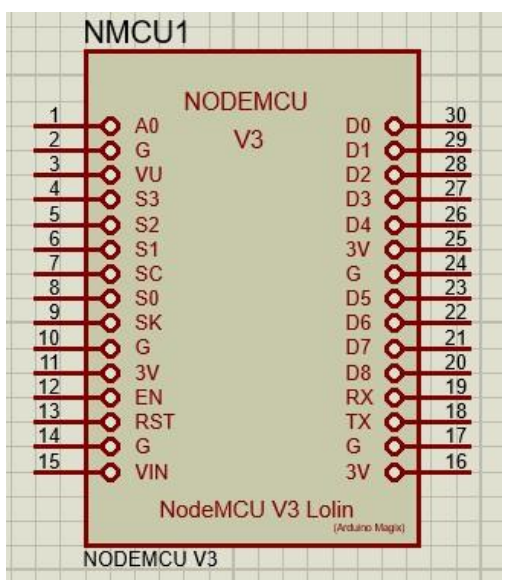

Gambar 4. NodeMcu

\section{b. LED}

Yaitu Light Emitting Diode atau bisa di sebut LED adalah komponen alat elektronika yang dapat memancarkan cahaya monokromatik ketika di beri suatu tegangan. LED juga bisa memancarkan cahaya infrared yang tidak bisa di ketaahui oleh indera mata seperti yang sering kita jumpai.

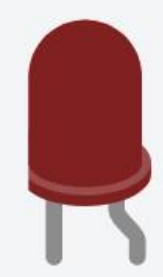

Gambar 5. LED

c. Water Level Sensor

Yaitu sensor yang di gunakan untuk mendeteksi ketinggian air dengan output lainnya kemudian di gabungkan menggunakan mikrokontroler. Cara kerja nya yaitu sensor ini membaca ketinggian air yang mengenai garis pada sensor, jadi semakin banyak air yang mengenai lempengan, maka semakin kecil resistansinya dan sebaliknya.

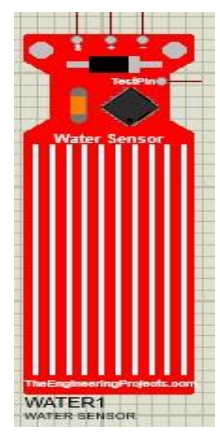

Gambar 6. Water Level Sensor

\section{d. Motor Servo}

Yaitu komponen elektronika yang berupa motor yang memiliki sistem feedback guna memberikan informasi posisi putaran motor actual yang di teruskan pada rangkaian kontrol mikrokontroller. Pada dasarnya motor servo banyak di gunakan dalam pembuatan aplikasi, beberapa hasil pembuatan yang menggunakan alat motor servo: Robotic Arms, floodgate dan lain lain nya

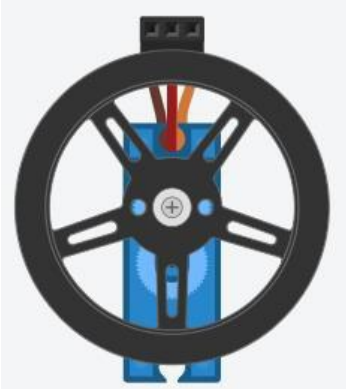

\section{Gambar 7. Motor Servo}

\section{e. Buzzer}

Yaitu komponen elektronika yang dapat mengubah sinyal listrik menjadi getaran suara, buzzer ini bisa di pakai untuk sistem alarm, buzzer ini tergolong komponen tranduzer, buzzer Cuma memiliki 2 dudukan yaitu positif dan negative

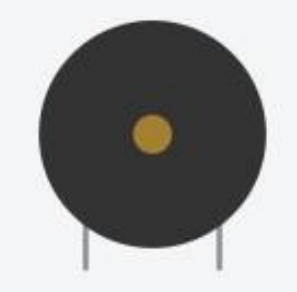

Gambar 8. Buzzer

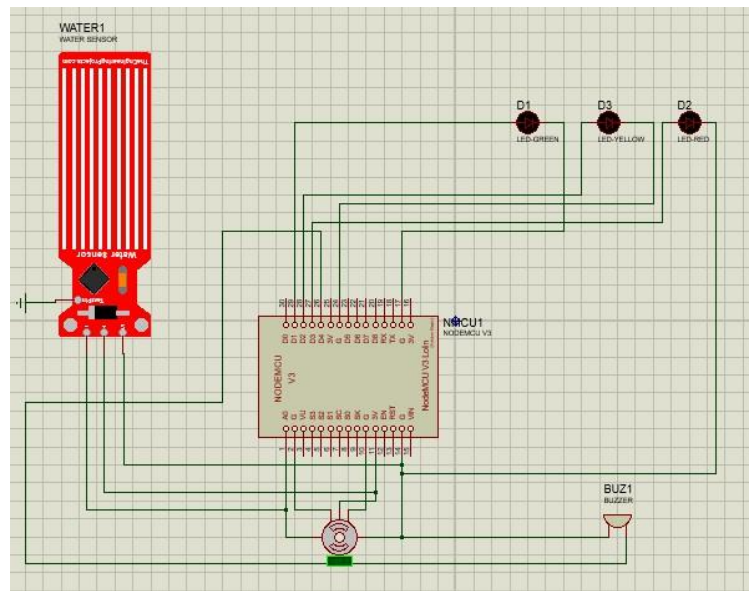

Gambar 9. Skema Alat Deteksi Ketinggian Banjir 


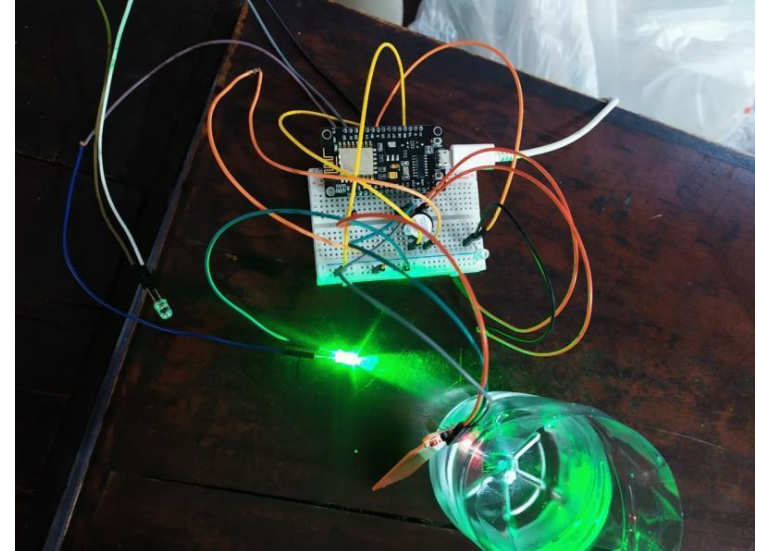

Gambar 10. Rancangan Alat Deteksi Ketinggian Banjir

Disini peneliti menggunakan alat yang di rangkai seperti gambar 8 . Penjelasan cara kerja alat nya yaitu nanti NodeMcu nya sebagai wifi untuk mengkoneksikan ke blynk agar bisa di monitoring melewati seluler, dan untuk sensor nya nanti akan di pasang di pinggir sungai, kali atau bendungan, dan nanti nya sensor tersebut akan membaca jika ada air yg sudah mengenai garis dan nanti sensor nya akan di atur untuk batasan nya berapa saja, nanti akan di bagi 3 batasan yaitu batasan bawah aman, batasan tengah waspada, dan batasan atas itu bahaya, dan nanti jika air tersebut menyentuh batasan bawah berarti status masih AMAN dan LED akan menyala warna HIJAU, dan jika air sudah menyentuh batasan tengah berarti status sudah WASPADA maka LED akan menyala warna KUNING dan buzzer akan nyala Cuma sekali untuk menandakan bahwa sudah mau mendekati bahaya, dan jika air sudah mencapai batas atas berarti status sudah mencapai BAHAYA maka LED akan berwana MERAH dan buzzer akan menyala terus menerus menandakan bahwa ketinggian air sudah mencapai status bahaya, dan nanti Motor servo akan membuka pintu air tersebut.

\section{HASIL DAN PEMBAHASAN}

\subsection{Uji Coba Aplikasi}

Pada sub bab ini peneliti akan melakukan uji coba terhadap aplikasi perangkat nya yaiut terdiri dari ujicoba alat, uji coba pengiriman data dan ujicoba algoritma background subtraction, untuk uraian penjelasan nya sebagai berikut.

Tabel 1. Uji coba Aplikasi

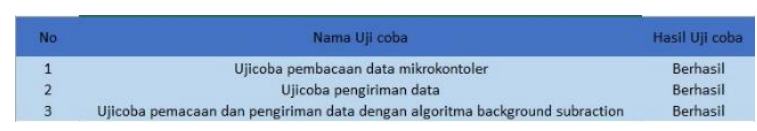

Tabel 2. Hasil Keakuratan

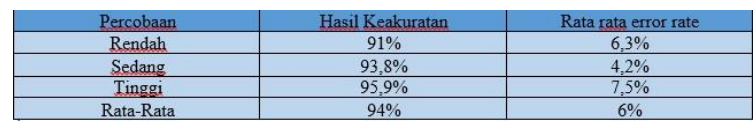

\subsection{Uji Coba Fungsionalitas Aplikasi}

Pada hasil pengujian fungsionalitas pada sistem yang telah dikerjakan dapat di lihat hasilnya. Pada tabel 1. Dapat di analisa bahwa semua fitur yang di uji pada sistem deteksi ketinggian banjir menggunakan mikrokontoler NodeMcu dapat diimplementasikan. Dan tingkat keberhasilan pada ujicoba dapat dikatakan aplikasi berjalan dengan sangat baik.

\subsection{Uji Coba Tingkat Keakuratan}

Dalam percobaan dengan ketiga kategori yang sudah di lakukan, dapat diketahui bahwa penggunakan sensor water level pada sistem deteksi ketinggian banjir cukup akurat. Dari beberapa kali percobaan dan perbedaan hasil tiap kategori cukup signifikan, data keakuratan nya bisa di lihat pada tabel 2. Dapat di simpulkan bahwa penggunaan sensor water level cukup mampu membaca ketinggian air tersebut

\subsection{Uji Coba Pengiriman Data}

Pada ujicoba kali ini sistem ini akan mengirimkan data, tapi data tersebut akan muncul secara realtime, dan data nya dapat di pantau melalui aplikasi arduino di serial monitor, saat aplikasi di jalankan maka data nya akan selalu muncul, dari percobaan ini waktu rentang pengiriman data dari sistem ke aplikasi bekisar sekitar 5 sampai 10 detik.

\subsection{Uji Coba Water Level Sensor}

Pengujian ini menilai keakuratan sensor monitoring dan pendeteksi menggunakan sensor water level, pengujian yang di lalukan penelitian ini mengukur ketinggian air

Tabel 3. Data Uji coba Sensor

\begin{tabular}{|c|c|c|c|c|c|c|}
\hline $\begin{array}{c}\text { Pembanding } \\
\text { Mistar (m) }\end{array}$ & $\begin{array}{c}\text { Tampilan } \\
\text { ukuran } \\
\text { sensor } \\
\text { water level }\end{array}$ & Buzzer & LED & Status & $\begin{array}{c}\text { Relatif } \\
\text { Error }(\%)\end{array}$ & $\begin{array}{c}\text { Motor } \\
\text { Servo }\end{array}$ \\
\hline 0 & 0 & OFF & HUAU & AMAN & 0 & TUTUP \\
\hline 1 & 1 & OFF & HUAU & AMAN & 0 & TUTUP \\
\hline 2 & 2 & OFF & HUAU & AMAN & 0 & TUTUP \\
\hline 3 & 3 & OFF & KUNING & WASPADA & 0 & TUTUP \\
\hline 4 & 4 & OFF & KUNING & WASPADA & 0 & TUTUP \\
\hline 5 & 5 & OFF & KUNING & WASPADA & 0 & TUTUP \\
\hline 6 & 6 & ON & KUNING & WASPADA & 0 & TUTUP \\
\hline 7 & 7 & ON & MERAH & BAHAYA & 0 & BUKA \\
\hline 8 & 8 & ON & MERAH & BAHAYA & 0 & BUKA \\
\hline 9 & 9 & ON & MERAH & BAHAYA & 0 & BUKA \\
\hline 10 & 10 & ON & MERAH & BAHAYA & 1 & BUKA \\
\hline
\end{tabular}

Hasil pengukuran dengan menggunakan sensor water level, dapat di cari dengan menggunakan error relatif yaitu (1).

\subsection{Uji Coba Parameter Jarak dan Sudut IP Camera terhadap Sensor Water Level}

Pengukuran jarak meter dan sudut ip camera terhadap sensor water level juga di ujikan karna untuk mendapatkan jarak minimum dan jarak maksimum. Jarak jangkauan minimum adalah jarak ambang 
sangat dekat dengan IP kamera yang dapat mendeteksi skala penunjukan, sedangkan jarak jangkauan maksimum adalah dimana IP kamera tidak dapat mencapai skala penunjukan level ketinggian.

Ujicoba pertama dilakukan dengan menguji jarak minimum IP kamera, berikut langkah langkah pengujian mencari jarak minimum yaitu :

1. Mengarahkan ip kamera ke skala penunjukan level ketinggian air.

2. Posisi kamera di dekatkan dengan level ketinggian air sehingga jarak minimum.

3. Kemudian di analisis menggunakan matlab yang telah di buat codingan program nya.

4. Proses ini dicoba/diuji sebanyak 10x.

Dari pengujian jarak minimum dengan pengenalan ke sensor water level di dapatkan jarak minimum $300 \mathrm{~cm}(3 \mathrm{~m})$, sedangkan pengujian jarak maksimum IP kamera terhadap dan di ujicoba dengan secara berulang sebanyak 10x, jarak maksimum yang di dapatkan yaitu $800 \mathrm{~cm}(8 \mathrm{~m})$.

Jarak jangkauan dan jarak sudut kamera berdasarkan identifikasi pengenalan IP kamera terhadap skala penunjukan gambar terdapat pada Gambar jarak IP kamera dan Gambar sudut IP kamera, untuk sudut kamera yang digunakan yaitu

15, 30, 45, 60, 75 dan 90 derajat. Pada jarak 300 $\mathrm{cm}$ menggunakan sudut kamera 30, 45 dan 60 derajat, ketinggian air dapat di analisa dan dapat terdeteksi, pada jarak $600 \mathrm{~cm}$ sudut kamera yang terlacak hanya 75 dan $90 \mathrm{~cm}$, sedangkan pada jarak $800 \mathrm{~cm}$ tidak ada sudut kamera yang dapat terdeteksi.

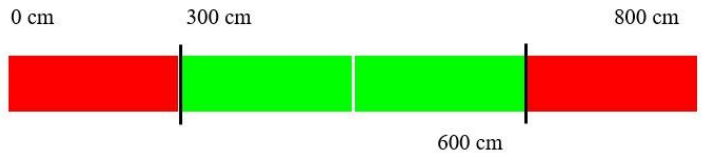

Gambar 11. Optimal Jarak Penemaptan IP Camera

Hasil pengujian jarak IP sudut kamera dapat di lihat pada tabel 5 .

\begin{tabular}{|c|c|c|c|}
\hline \multirow{2}{*}{ Sudut $\left({ }^{\circ}\right)$} & \multicolumn{3}{|c|}{$\operatorname{Jarak}(\mathrm{cm})$} \\
\cline { 2 - 4 } & $300 \mathrm{~cm}$ & $600 \mathrm{~cm}$ & $800 \mathrm{~cm}$ \\
\hline 15 & $\times$ & $\times$ & $\times$ \\
\hline 30 & $\sqrt{ }$ & $\times$ & $\times$ \\
\hline 45 & $\sqrt{ }$ & $\times$ & $\times$ \\
\hline 60 & $\sqrt{ }$ & $\times$ & $\times$ \\
\hline 75 & $\times$ & $\sqrt{ }$ & $\times$ \\
\hline 90 & $\times$ & $\sqrt{ }$ & $\times$ \\
\hline
\end{tabular}

Keterangan $: \sqrt{ }=$ Terdeteksi $\quad x=$ Tidak terdeteksi

\section{KESIMPULAN}

Dari penelitian yang telah dilakukan dapat disimpulkan bahwa:

a. Sensor water level mampu bekerja dengan sangat baik dengan tingkat akurasi nya $96 \%$ dalam pengukuran deteksi ketinggian air yang berubah- ubah, dengan tingkat relatif error yang sangat minim yaitu $4 \%$, bahwa semua dapat berjalan dengan sesuai perintah, jadi saat air berada pada ketinggian 0-2 $\mathrm{m}$ maka status akan menandakan AMAN dan led akan berwarna hijau, jika ketinggian air mencapai 3-6 m maka status akan menandakan WASPADA dan led akan berwarna kuning, tapi jika ketinggian $6 \mathrm{~m}$ status masih WASPADA, tapi buzzer akan menyala Cuma 1-2 kali untuk menandakan bahwa status akan mencapai ke level BAHAYA, dan selanjutnya jika ketinggian air sudah mencapai 7-10 m maka status akan menandakan BAHAYA dan led akan berwarna merah, buzzer pun akan menyala untuk menandakan bahwa status sudah BAHAYA dan akan secara otomatis motor servo akan membuka tutup pintu air tersebut ke dataran yang lebih luas.

b. Hasil pengujian pada lokasi tersebut menampilkan jarak jangkauan IP kamera yang masih menunjukan skala pada mendeteksi ketinggian air yaitu pada jarak $300 \mathrm{~cm}$ sampai $600 \mathrm{~cm}$ dengan sudut 30 , $45,60,75,90 \mathrm{~cm}$, sedangkan jarak $800 \mathrm{~cm}$ tidak dapat

\section{DAFTAR PUSTAKA}

A. Diriyana et al., "Water Level Monitoring and Flood Early Warning Using Microcontroller With IoT Based Ultrasonic Sensor," J. Tek. Inform. C.I.T, vol. 11, no. 1, pp. 22-28, 2019, [Online]. Available:

www.medikom.iocspublisher.org/index.p $\mathrm{hp} / \mathrm{JTI}$.

A. Muzakky, A. Nurhadi, A. Nurdiansyah, and G. Wicaksana, "Perancangan Sistem Deteksi Banjir Berbasis IoT," Conf. Innov. Appl. Sci. Technol. (CIASTECH 2018), no. September, pp. 660-667, 2018, [Online]. Available: http://publishingwidyagama.ac.id/ejournalv2/index.php/ciastech/article/viewFile/67 $8 / 629$.

Respatiningsih, I. A. Bangsa, and A. Stefanie, "Perancangan Sistem Monitoring Dan Pendeteksi Banjir Menggunakan Metode Background Subtraction Berbasis Internet Of Things ( IOT )," SeminarFORTEI, pp. 97-100, 2019.

S. P. Windiastik et al., "Perancangan Sistem Pendeteksi Banjir Berbasis IoT (Internet Of Thing)," no. September, pp. 19251931, 2019, [Online]. Available: https://jurnalfti.unmer.ac.id/index.php/sen asif/article/download/256/216/.

E. B. Lewi, U. Sunarya, and D. N. Ramadhan, "Sistem Monitoring Ketinggian Air Berbasis Internet of Things Menggunakan 
Google Firebase," Univ. Telkom, D3 Tek. Telekomun., vol. 1, no. 1, pp. 1-8, 2017.

S. Kom and M. Kom, "SISTEM PENGAMANAN PINTU RUMAH BERBASIS Internet Of Things ( IoT ) Dengan ESP8266," vol. 7, no. 4, pp. 262-268, 2016.

C. Prabowo and Zurnawita, "Penerapan Metode Background Subtraction Dengan Menggunakan Kandidat Sampling Background Applied Background Subtraction Method Used Background," J. Teknol. Inf. dan Ilmu Komput., vol. 5, no. 6, pp.731-736, 2018, doi: 10.25126/jtiik201856115.

S. I. Abdullahi, M. H. Habaebi, and N. A. Malik, "Intelligent flood disaster warning on the fly: Developing IoT-based management platform and using 2-class neural network to predict flood status," Bull. Electr. Eng. Informatics, vol. 8, no. 2, pp. 706-717, 2019, doi: 10.11591/eei.v8i2.1504.

H. Yuliandoko, Subono, V. A. Wardhany, S. H. Pramono, and P. Siwindarto, "Design of flood warning system based IoT and water characteristics," Telkomnika (Telecommunication Comput. Electron. Control., vol. 16, no. 5, pp. 2101-2110, 2018 ,

doi:10.12928/TELKOMNIKA.v16i5.763 6. 